\title{
Strength Analysis of the CNG Direct Injector for the Combustion Ignition Engine in Real Driving Conditions
}

\author{
Pawet Magryta ${ }^{1, *}$, Michat Gęca ${ }^{1}$, and Michał Biały ${ }^{1}$ \\ ${ }^{1}$ Faculty of Mechanical Engineering, Department of Thermodynamics, Fluid Mechanics and Aviation Propulsion Systems, \\ Lublin University of Technology, ul. Nadbystrzycka 36, 20-618 Lublin, Poland
}

\begin{abstract}
The paper presents the results of strength test simulations of the CNG injector structure for direct injection of compression-ignition engines. This article is a continuation of the works presented in paper [1]. Life cycles estimation of particular parts of the injector were calculated using the Kocanda relation. The simulation tests of injector strength carried out earlier have allowed us to determine the stress concentration points. On the basis of NEDC driving tests carried out in three different cars, engine load histograms were made for subsequent runs and an average load profile was determined. For the points most exposed to damage, i.e. the needle and injector housing, the stress curve was generated as a function of time. This dependence was the base for fatigue calculations with the use of MatLab program in order to calculate the limit number of repetitions for a given injector element. All the calculation works have served to determine the maximum number of work cycles of a given injector design.
\end{abstract}

\section{Introduction}

The use of simulation studies for design optimisation is now commonplace. Until recently, mainly due to the lack of access to computers with high computing power, it was not possible to perform strength and fatigue analysis of complex structures. The formerly applied analytical methods were efficient but based on simple mathematical relationships that were suitable for static loads on the structure. Nowadays, access to a wide range of simulation software (strength, fatigue, etc.) allows for substantial reductions in the designing time and optimisation of new structures $[1,2]$. This applies mainly to machine elements operating under extreme loading conditions. In the automotive industry, especially in recent times, there has been a multiplefold increase in the usability of this type of software [1].

Fatigue strength calculations of machine elements, must account for the fatigue strength (fatigue limits) $Z$ for various cycles. For this purpose, fatigue diagrams, e.g. Smith and Haigh diagrams [3], are prepared for a given material and for a given load type. The obtained graph is sufficient to perform calculations for plastic materials (steel, non-ferrous metal alloys) [4]. Fatigue strength (fatigue limit) $Z_{G}$ is the highest stress (for a specific stress cycle) at which the element does not fail. The index $G$ can be replaced depending on the load type with ( $r$ - tension; $c$ - compression; $g$ - bending; $s$ torsion; $o$ - pendulum cycle; $j$ - bicycle, unilateral). The determination of the maximum stress at which the component does not fail is not unambiguous. For the sake of this analysis, failure will be understood in two ways: as complete separation of the component into two parts, as well as the state of the material in which non-destructive defectoscopy methods are used to determine the existence of cracks in the component. The number of cycles to failure $N_{i}$ is given in the material data.

For several years now, the automotive industry has been putting more and more emphasis on the use of alternative fuels for powering combustion engines [5]. LPG has become a widely popular alternative fuel in Poland [2]. Its widespread use is generally attributed to an uncomplicated installation of an additional alternative fuel supply system in almost every car originally fuelled with petrol. Current research works aim to explore the possibility of powering compression-ignition engines with this fuel $[6,7,8,9$, 10]. However, along with the development of LPG fuelling methods, the same emphasis is placed on the dissemination of $\mathrm{CNG}$ fuelling of combustion engines. There are currently cars that are factory-fitted with engines designed to run on CNG. However, the possibility to adapt the engine already in operation to the CNG fuelling capabilities (similarly as it is currently the case for positive-ignition and LPG engines) does seem to offer an interesting perspective. Nevertheless, such a modification in the case of CNG and diesel engines is more complicated than with LPG and petrol engines. The majority of currently installed LPG installations use the so-called indirect power supply, i.e. the supply of gas to the engine intake system. An attempt at developing such a solution in the case of $\mathrm{CNG}$ and diesel engine causes exceeding a certain percentage dose of gaseous fuel in relation to diesel fuel, which in turn results in the occurrence of a

* Corresponding author: p.magryta@pollub.pl 
dangerous knocking combustion phenomenon. The necessity to limit the amount of substitute fuel to about $20-30 \%$ is the major challenge from the economic perspective. On the other hand, dual-fuel mode presents certain drawbacks at low loads, particularly concerning unburned hydrocarbon UHC and $\mathrm{CO}$ emissions [11]. Inadequate dosage of the original fuel substitute effectively hinders the largescale spread of this technology (comparable to LPG). For this reason, the only possible solution is to apply direct injection of $\mathrm{CNG}$ fuel into the chamber of a compression ignition engine. Certain technological solutions already available on the market base on the use of dual diesel injectors and CNG. WestPort-Cycle technology contains High Pressure Direct Injection (HPDI) of natural gas with a diesel pilot ignition source. Both fuels are delivered through a single, dual common rail injector. The operating cycle is entirely unthrottled and maintains a high compression ratio of a diesel engine.

In order to disseminate the use of $\mathrm{CNG}$ gas in compression ignition engines, we propose to use an innovative $\mathrm{CNG}$ injector to be placed in the position of a glow plug to supply gaseous fuel. The lack of a glow plug may cause a problem with initiating the combustion of the air/fuel mixture, which is however easily solved by the use of a pilot dose of diesel fuel injected by the original diesel injector. The presented concept of alternative diesel fuel supply is related to the current research project supported by the Polish National Centre for Research and Development under the grant No. PBS1/A6/4/2012. As part of this project, a CNG gas supply system for diesel engine has been developed. One of the crucial elements of this system is the CNG gas injector. The design of the injector is the result of previously conducted optimisation tests modifying the flow conditions of $\mathrm{CNG}$ gas, its distribution and combustion in the engine chamber, as well as in terms of endurance and fatigue tests, which will be discussed in this article.

\section{Material and methods}

The tested object is a CNG gas injector for direct supply to the diesel engine. The design of the injector adopted for testing has been developed and optimised for the conditions necessary to ensure proper operation of the Andoria ADCR engine [1]. This engine is a 4-stroke compression-ignition engine. It has been selected as a representative unit for use in medium sized passenger cars and vans. Figure 1 shows the analysed elements of the injector: needle and housing.

Simulation and strength tests presented in the article were performed with the use of several programs to ensure the most reliable results. The computational sequence of programmes employed in the tests was as follows:

- one-dimensional modelling of engine parameters AVL Boost,

- 3D design - Catia v5,

- multibody software - MSC Adams,

- strength calculations - Abaqus,
- MatLab fatigue calculations.

The overall design process used to obtain the results of fatigue calculations proceeded as follows. First of all, the geometry of the injector was designed in Catia v5 program. The next stage in which the boundary conditions applied in the model were determined was $1 \mathrm{D}$ modelling in AVL Boost software. It is software used to calculate the working process models of internal combustion engines. Similar engine models with ZI are described by the authors in [12] and the engine with ZS in [13]. Subsequently, on the basis of data obtained from AVL Boost program, the values of forces acting on the injector, which resulted from the engine working process, were introduced into MSC Adams. This enabled us to use the MSC Adams model MSC Adams to determine the curve of dynamic forces that accompany the process of closing and opening the injector. All this information together allowed enabled the development of boundary conditions for strength simulation in the Abaqus program. The results of this simulation were used as input for the fatigue analysis developed in MatLab.

A comprehensive diagram of the information flow between the individual software elements of the set-up is shown in Figure 2. In order to optimise the injector design, the process of subsequent calculations was repeated several times.

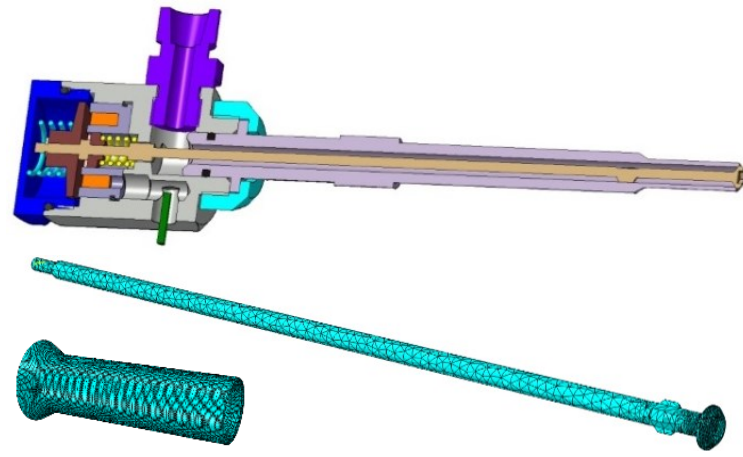

Fig 1. The analysed injector and its active elements (needle and housing) - design I.

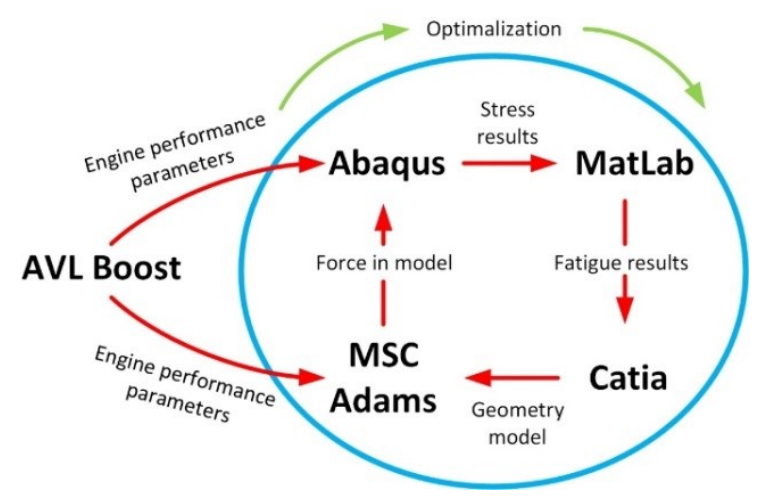

Fig. 2. Calculation process.

Simulation tests presented in the article mainly concern fatigue analysis during the opening and closing of the injector. This injector will work in unfavourable thermal and stress conditions. However, the thermal loading processes of the injector structure were not 
accounted for in calculations - as it is a separate issue. In order to reflect the conditions of the injector in each of the above-mentioned programs a model of the injector has been created. Due to the specificity of the injector's work, i.e. repeated cycle of opening and closing, the main processes occurring at the contact surface of the needle and housing were analysed.

Fatigue analysis was performed on gas injector elements, i.e. needle and housing, which were checked for strength. The material for the needle was steel NW1 (EN107CrV3), and for the needle housing steel 45 (EN C45). Additionally the pressure from combustion chamber was added at the outer parts of injector nozzle with the value of $10.52 \mathrm{MPa}$. There was no temperature boundary condition.

The results obtained from the FEM programme (Abaqus) were used for fatigue calculations. The conducted strength analysis has led to the determination of the places exposed to stress concentration. Since the endurance analysis was performed at the diesel engine operating point determined by the highest power and constant speed of $3500 \mathrm{rpm}$, the fatigue analysis was performed under identical conditions. Admittedly, the conditions during engine operation might require different power demand, but for the sake of limiting the calculation time, the highest value of the stress waveform was assumed.

In order to obtain the stress pattern at selected critical points of individual elements, approximately 21 cases of calculations were performed for different engine crankshaft rotation angles in the range of 0 $720^{\circ}$. The next step was to determine the function characterising the dependence of loading boundary conditions on the amount of obtained stress. On this basis, the full stress curve was determined as a function of engine crankshaft rotation. Consequently, this has allowed us to calculate the fatigue strength of the tested elements and time between overhauls in hours (TBO).

Input data for preliminary and final calculations (after modification of the structure) of fatigue calculations are as follows:

1. time signal of stress curve in individual elements constructed on the basis of strength calculations (Figures 3 and 7),

2. operational driving spectrum (Table 1), containing the weights of vibration load amplitudes for each engine load condition while driving and the time shares of the individual driving conditions in which the specified loads occur.

3. material data:

a) fatigue strength value $\left(z_{r j}\right.$ - fatigue limit for zero stress pulse tensile test), determined from the empirical relationship $z_{r j}=0.55 \mathrm{R}_{\mathrm{m}}$ or from the material data at the limit number of cycles $N_{i}=107$ for the needle,

b) fatigue strength value $\left(\mathrm{z}_{\mathrm{rc}}\right.$ - limit of compression fatigue, tensile strength), determined on the basis of empirical relation $Z_{r c}=0.33 \mathrm{R}_{\mathrm{m}}$ or from material data at the limit number of cycles $N_{i}=107$ for the firing pin body and the firing pin itself.

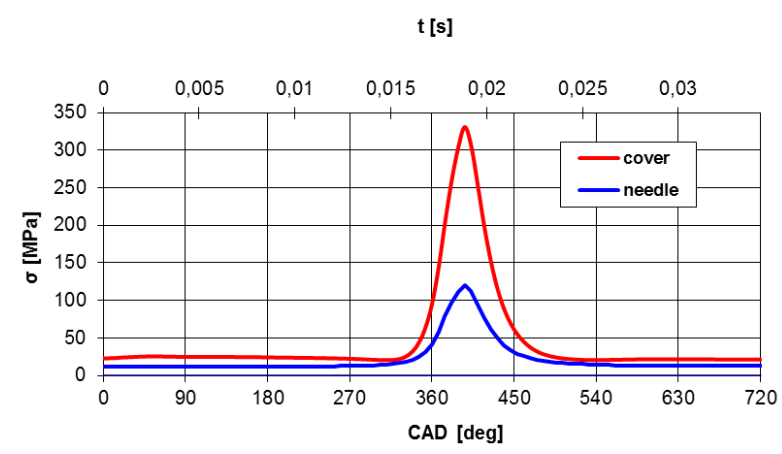

Fig. 3. The stress curves of individual elements of the gas injector test - design I.

Calculation methodology:

1. multiplication of a single load cycle up to time $t c$ $10 \mathrm{~s}$,

2. generation of a vibration load signal for the entire analysed time interval $t c$, assuming sampling rate $f_{s v}=400 \mathrm{~Hz}$ for one vibration cycle,

3. calculation of the amplitude of equivalent loads reduced to the mean value (the value 0 was assumed) for each of the states in the load spectrum calculation is based on the hypothesis of fatigue damage accumulation and the hypothesis of the influence of the mean value on fatigue according to Odinga-Topper,

4. calculation of the number of $N_{0}$ load cycles per hour of engine operation based on the nominal frequency of $f e q v(3500 \mathrm{rpm})$

5. calculation of the number of hours at which the accumulated fatigue damage will be equal to the fatigue damage for the beginning of the reduced fatigue strength of $z g$ - then the converted Koćanda formula conditions are fulfilled.

These calculations were made for real conditions corresponding to the working conditions of the injector. From the conducted driving analyses for passenger cars based on the NEDC driving test, the working time of the injector, average engine speed and average load were determined. The average rotational speed was $1700 \mathrm{rpm}$ and the average engine load was $35 \%$. These calculations do not take into account the idling time of the engine, which is when the CNG gas is not dosed into the combustion chamber and the operating time of the engine during the engine braking process, when no fuel is delivered to the combustion chamber. Such boundary conditions changed the total simulation time in all models and the moment of injector closing.

The number of cycles after which the element will be destroyed is determined on the basis of the Kocańda relationship between:

$$
N_{0}=\frac{\sum \delta^{m} \cdot N_{i}}{z_{g}^{m}}
$$

where:

$\delta$ - sum of the reduced loads,

$n_{i}$ - number of cycles to failure,

$m$ - cotangents of straight inclination on the Wöhler diagram, 
$N_{i}$ - number of cycles to failure.

The sum of the reduced loads consists of the values of thermal loads and vibrations. Their amplitude is reduced to the mean value (assumed as 0). The calculations are based on the hypothesis of accumulation of fatigue damage and the hypothesis of influence of mean value on fatigue according to OdingaTopper [14].

According to the PN-H-04325:1976 standard, the $N_{i}$ value for steel is $10^{7}$ cycles, and for non-ferrous metals and alloys it is within the limits: $2 \times 10^{7}-10^{8}$ cycles depending on the type of alloy. The range, in which $N_{0}<N_{i}$, is called the range of limited fatigue strength.

The values of the exponent $m$ depend mainly on the type of material, the shape of the element and the properties of the surface layer. For polished elements made of various types of steel $m=9-12$, equipped with the most common notches $m=6-10$, after various surface treatments $m=18-20$.

\section{Results of operational tests}

For fatigue calculations, the operational driving spectrum was obtained, including weights of amplitude of loads from vibrations for each engine load conditions during driving and time shares of particular driving conditions in which the above-mentioned loads occur. The tests were carried out in three vehicles: Skoda, Volkswagen, Renault. In each case, data from EOBD transmissions were recorded at a frequency of $10 \mathrm{~Hz}$. Three tests were carried out for each vehicle driven in urban and extra-urban (out-of-town) conditions. On the basis of these measurements, engine load histograms were created for subsequent journeys and average load profiles determined ( 3 vehicles, 3 journeys, urban and extra-urban). Average results from 9 urban driving profiles are presented in percentage scale in Figure 4 and Table 1, and in the case of extra-urban driving in Figure 5 and Table 2.

Road tests have shown that a diesel vehicle can reach a maximum of more than $90 \%$ of the load, which represents $10 \%$ of all loads in urban traffic, and less than $3 \%$ in extra-urban traffic.

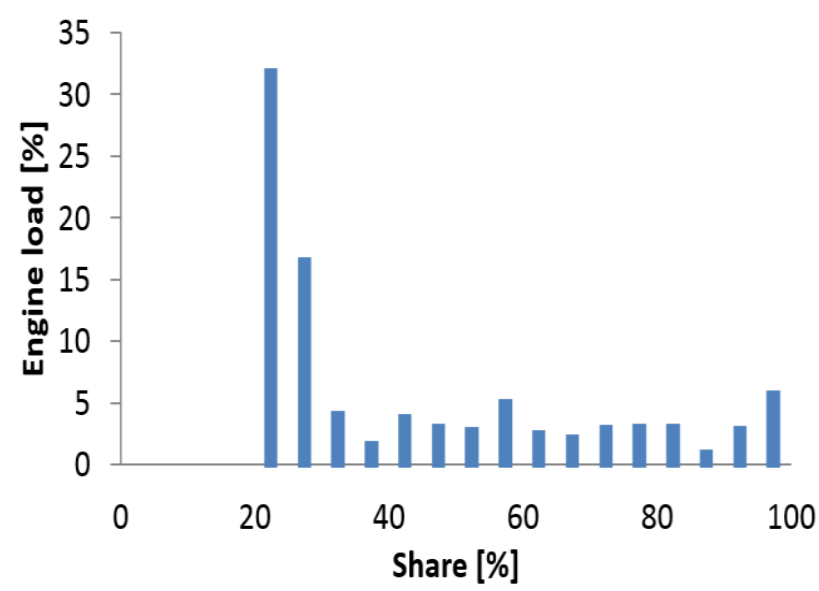

Fig. 4. Average load values for diesel engine operating in urban conditions.
Table 1. Average load values for diesel engine operating in urban and extra-urban conditions.

\begin{tabular}{|c|c|c|}
\hline Engine load [\%] & $\begin{array}{c}\text { Share (urban) } \\
{[\%]}\end{array}$ & $\begin{array}{c}\text { Share (extra } \\
\text { urban) [\%] }\end{array}$ \\
\hline 22.50 & 32.11 & 26.61 \\
\hline 27.50 & 16.95 & 32.02 \\
\hline 32.50 & 4.56 & 13.99 \\
\hline 37.50 & 2.14 & 6.92 \\
\hline 42.50 & 4.36 & 4.93 \\
\hline 47.50 & 3.57 & 3.47 \\
\hline 52.50 & 3.29 & 2.38 \\
\hline 57.50 & 5.54 & 1.88 \\
\hline 62.50 & 3.07 & 1.27 \\
\hline 67.50 & 2.73 & 1.31 \\
\hline 72.50 & 3.44 & 1.14 \\
\hline 77.50 & 3.54 & 0.72 \\
\hline 82.50 & 3.56 & 0.24 \\
\hline 87.50 & 1.47 & 0.59 \\
\hline 92.50 & 3.39 & 0.31 \\
\hline 97.50 & 6.26 & 2.23 \\
\hline
\end{tabular}

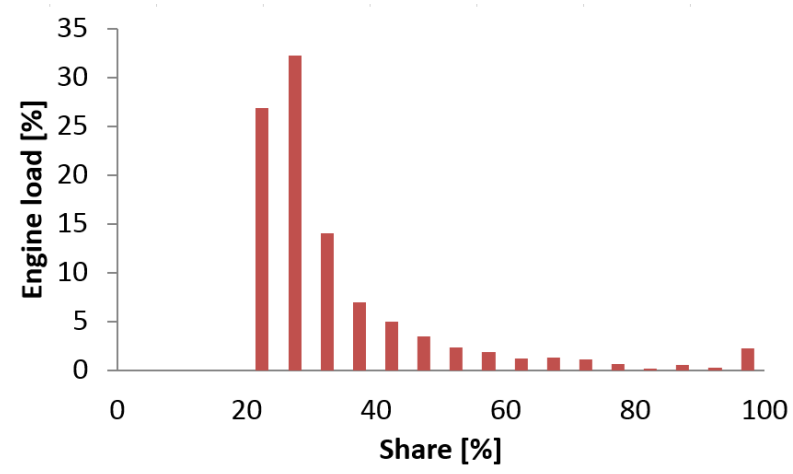

Fig. 5. Average load values for a diesel engine operating in extra-urban conditions.

\section{Calculation results}

Fatigue calculations were carried out for 4 scenarios of injector operation:

1. $100 \%$ of engine load during its entire lifetime,

2. $40 \%$ (on average) of the engine load over its entire service life,

3. engine loads taking into account the spectrum during urban and extra-urban driving (Table 1),

Table 2. Results of preliminary strength calculations of injector elements - design I.

\begin{tabular}{|c|c|c|}
\hline & needle & housing \\
\hline I [h] & 138.000 & 119 \\
\hline II [h] & 33697.521 & 29.192 \\
\hline III [h] & 56050,435 & 116.118 \\
\hline IV [h] & 39892.887 & 82.645 \\
\hline
\end{tabular}

In Table 2, the needle body with limited fatigue strength is marked in red.

In the second series, calculations were made for modified geometry, in which the shape of the needle and the housing diameter were changed. The tip of the 
injector needle, seat in the casing and an additional element stabilising the longitudinal motion of the needle were changed. The complete final geometry is shown in Figure 6.

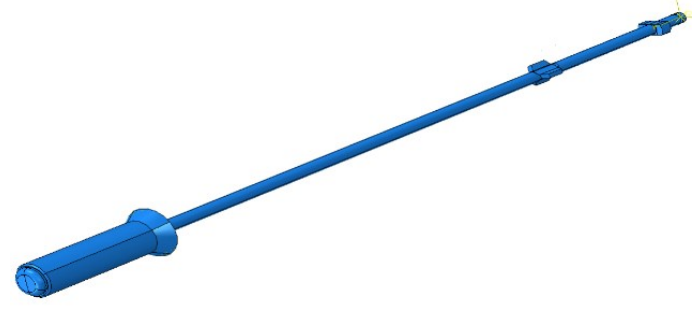

Fig. 6. Needle and housing assemblies for strength tests, final design.

Changed geometry allowed reducing stresses on the needle and housing (Table 3). Additionally, the stresses occurring on the main part of the firing pin were checked.

The following Figure shows the stress course in the modified injector.

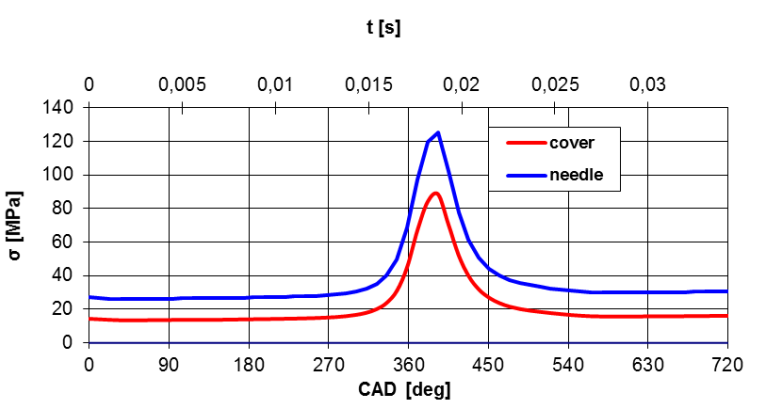

Fig. 7. The course of stresses in individual elements of the gas injector test after modification.

Table 3. Results of strength calculations of injector elements (modified) - design II.

\begin{tabular}{|c|c|c|}
\hline & needle & housing \\
\hline I [h] & 162753 & 1074226 \\
\hline II [h] & 39734815 & 262262368 \\
\hline III [h] & 66092506 & 436231483 \\
\hline IV [h] & 47040150 & 310479895 \\
\hline
\end{tabular}

\section{Summary}

The initial fatigue calculations proved that the needle body is the element of the injector most susceptible to damage. It should be emphasised that failure in fatigue calculations means deformation of the tested elements. In the case of the injector under test, the needle and body are pairs of common contact. Fatigue processes will result in additional sealing of the cooperating elements. In most of the manufactured gas systems equipped with gas injectors, after the mileage of about several thousand kilometres, the injectors are rearranged and the system requires recalibration. Taking into account the average speed during the life of the vehicle, $50 \mathrm{~km} / \mathrm{h}$, the body will be damaged after about 6 thousand kilometres in the assumed first load scenario. The needle under the same conditions will not be destroyed after less than 7 million $\mathrm{km}$. These are the extreme conditions in which the maximum engine load of the vehicle occurs. Assuming 40\% engine load over the entire lifetime (load scenario II), the most vulnerable element, the firing pin body, will withstand a mileage of about 1.5 million $\mathrm{km}$.

Preliminary calculations for III and IV load scenarios showed unlimited strength of injector components.

Basic fatigue calculations will take into account not only the gas force, but also the spring tension force, thermal stresses and stresses from the phenomenon of repeated impact of the needle on the body during the closing of the injector observed during the calibration of the injector on the measuring set-up.

\section{Acknowledgements}

This work has been financed by the Polish National Centre for Research and Development, under Grant Agreement No. PBS1/A6/4/2012.

\section{References}

1. P. Magryta, M. Wendeker, R. Sochaczewski, A. Majczak, Combustion Engines 54, 3, 425-431 (2015)

2. R. Sochaczewski, Z. Czyż, K. Siadkowska, Combustion Engines 170 (2017)

3. S. Kocańda, J. Szela: Podstawy obliczeń zmęczeniowych (PWN, Warsaw, 1985)

4. S. Kocańda: Zmęczeniowe pękanie metali (WNT, Warszawa, 1985)

5. K. Siadkowska, M. Wendeker, A. Majczak, G. Baranski, M. Szlachetka (SAE Technical Paper 2014-01-2611, 2014)

6. A. Majczak, G. Barański, R. Sochaczewski, K. Siadkowska, ASTRJ 11, 212-219 (2017)

7. R.Sochaczewski, G. Baranski, A.Majczak, I. C. A. M. A. M. E. (2016)

8. R. Sochaczewski, M. Wendeker, G. Barański, A. Majczak, Combustion Engines 162, 442-448 (2015)

9. T. Tulwin, R. Sochaczewski, The dual-fuel CFD combustion model with direct and indirect $C N G$ injection (WOS, 2017)

10. M. Bialy, M. Wendeker, P. Magryta, Z. Czyz, R. Sochaczewski, CFD Model of the Mixture Formation Process of the CNG Direct Injection Engine (SAE, 2014)

11. Yousefi, Amin \& Birouk, Madjid, Applied Energy, Elsevier, 189(C), 492-505, 2017.

12. Z. Czyz, L. Grabowski, K. Pietrykowski, J. Czarnigowski, M. Porzak, Measurement 113 (2018)

13. L. Grabowski, K. Pietrykowski, P. Karpinski, 2nd International Conference of Computational Methods in Engineering Science CMES (2017)

14. M. Dunn, State of the art and future developments in natural gas engine technologies (United states: n. P, 2003) 